\title{
Alternative Approaches to Configuring Computing Labs
}

\author{
Gokhan Gercek and Naveed Saleem \\ University of Houston-Clear Lake, Houston, TX 77058
}

\author{
Gercek@cl.uh.edu Saleem@cl.uh.edu
}

\section{Executive Summary}

Budgetary constraints are almost a constant challenge confronted by academia. In the case of small colleges and universities, these constraints become even more pronounced when these institutions enhance their programs to meet the needs of their constituents. While in some cases program enhancement might simply be accomplished by hiring new faculty members; in others, it might require additional resources. This is especially true for computer science or management information systems programs; the changes or enhancements in these programs also mean additional computing lab support. However, budgetary constraints, lack of physical space to house the labs, conflicting needs of different courses, and rapid obsolescence of technology only exacerbate this dilemma. Needless to say, overcoming these challenges requires some pragmatic thinking and approaches. Based on their own experiences in dealing with these same challenges, the authors suggest the following guidelines for configuring computing labs that are cost-effective, flexible and versatile:

- Categorize computing courses, based on their computing support requirement, into groups such as general computing, advanced computing, and special projects courses.

- As far as possible, support general computing courses through open/general labs and, thereby, minimize the demand for dedicated/special computing labs.

- The advanced computing courses will likely require dedicated labs, due to unique software and/or hardware requirements. For most institutions, creating a dedicated lab for every course is infeasible. Consequently, design a lab that can support multiple courses by use of removable hard drives and flexible lab configurations.

- If the physical space is not available to house a dedicated computer lab, a classroom may be networked into an isolated laptop-computing lab. To further enhance the flexibility of this lab, it may be connected to the institution's computing networks through wireless network configuration.

- For special projects, develop a dedicated computing lab with highly flexible configura-

Material published as part of this journal, either on-line or in print, is copyrighted by the publisher of the Journal of Information Technology Education. Permission to make digital or paper copy of part or all of these works for personal or classroom use is granted without fee provided that the copies are not made or distributed for profit or commercial advantage AND that copies 1) bear this notice in full and 2) give the full citation on the first page. It is permissible to abstract these works so long as credit is given. To copy in all other cases or to republish or to post on a server or to redistribute to lists requires specific permission and payment of a fee. Contact Editor@JITE.org to request redistribution permission. tion and infrastructure to accommodate the unique computing requirements of different projects. Furthermore, this lab should mimic the network and organizational configuration of a typical organization to impart real-life flavor to special projects. 
- With proper supervision, policies and procedures, student personnel may be employed to maintain and manage specialized labs. This will help contain personnel costs and at the same time furnish valuable experience to the student personnel.

These guidelines should help small U.S., as well as international, institutions that are planning or are in the process of configuring computing labs to support their computer science and management information systems programs.

Keywords: computing labs, general computing labs, dedicated computing labs, special projects computing labs, configuring a computing lab, designing a computing lab

\section{Introduction}

Within a matter of a few decades the computing function within the business, as well as nonbusiness, environment has evolved from a support function to an essential function. One would be hard pressed to name an industry that does not rely on computer systems to support its operations and decision-making. This reliance has resulted in increased demand for personnel with computer science and management information systems backgrounds. While large colleges and universities already have had such programs in place for quite some time, many small U.S. and international colleges and universities are just undertaking such endeavors. Introducing such programs mandates that the institutions must put in place the necessary computing labs to support the programs being introduced. However, in creating such labs, the institutions usually encounter significant obstacles, such as budgetary constraints, lack of physical space to house the labs, conflicting needs of different courses, and rapid obsolescence of technology (Andleman et al., 2003; Belles \& Miller, 2002; Dubose, 2000; Jones, 2000; Kumar, 2003;Lovgren, 2000; Walter, 1993; Wilson, 2002). The Management Information Systems (MIS) program at the University of Houston-Clear Lake (UHCL) faced the same daunting challenges when the program was introduced in late $90 \mathrm{~s}$. This paper presents the alternate computing lab configurations that were evolved to provide a cost-effective, flexible and versatile lab support for the MIS program within budgetary and space constraints.

\section{Computing Lab Support Challenges to UHCL/MIS Program}

University of Houston Clear Lake (UHCL) comprises four schools and offers graduate and undergraduate programs to more than 7000 students. The School of Business is the largest school in the university and includes a management information systems program, introduced in the mid 90 s, as a major discipline.

Since its inception, one of the challenges the UHCL/MIS department has been coping with is the lack of adequate dedicated computing labs. The problem resulted from budgetary constraints and lack of sufficient physical space to house the computing labs. A new building that is currently under construction will alleviate this problem and house four computing labs to support the MIS program. In the meantime, however, the MIS faculty and university computing personnel have had to devise some pragmatic solutions to provide computing lab support to the program in limited space and within budgetary constraints.

The following section presents the three primary categories of graduate MIS courses at UHCL and describes the computing resources required by each category for the students to complete course assignments, exercises, projects, etc. These computing requirements provided the catalyst for different lab configurations. 


\section{MIS Course Categories and their Computing Requirements}

The UHCL/MIS graduate courses can be grouped into the following three broad categories: (1) general computing courses, (2) advanced computing courses, and (3) special projects.

\section{General Computing Courses}

This category is comprised of courses that introduce students to a specific skill, technology or subject area. Typically, these courses don't have a pre-requisite in the same skill, technology or subject area; however, by themselves, directly or indirectly, they form pre-requisites to one or more courses. This category includes courses such as Introduction to Management Information Systems, Introduction to Computer Networks, Fundamentals of Database Design and Development, and Introduction to Business Applications Programming.

\section{Advanced Computing Courses}

The courses in this category include System Administration, Network Security, Advanced Database Applications, Database Administration, Advanced Business Applications Programming, and E-Commerce Applications. One of the distinguishing characteristics of these courses is that the students in these courses generally require administrative access and privileges on the workstations and servers to work on course assignments and projects.

\section{Special Projects}

This category consists of courses such as thesis, independent studies and research projects. Their requirements vary according to the specific course content and may be governed by some predefined guidelines or an understanding reached between the student who is working on the project and the instructor who is supervising the project; consequently, any suggestions to enhance the students' computing experience in this category of courses is not warranted.

\section{Alternate Computing Lab Configurations}

This section presents four alternate computing lab configurations, which individually can support courses from one or more categories, and as a group should meet the computing requirements of all categories of courses.

\section{Configuration 1: General Computing Labs}

A general computing lab is a network of servers and desktops designed to support the computing requirements of the first category courses, as well as students' general computing needs (Belles \& Miller, 2002; Dubose, 2000). More specifically, these labs are meant to support the common computing needs of multiple disciplines from all schools at the university, with little flexibility in their configuration. In these labs, the application and programming software are installed on servers, and the desktops are loaded with the client software to allow students to interact with servers. Prior to each semester, instructors convey their lab software requirements to the laboratory managers for installation of server and client software components at the servers and the desktops. Instructor's desktops in the classrooms are similarly configured as the desktops in the laboratories to allow the instructors to perform in-class demonstrations of the software tools. Furthermore, 
instructors may also request that the same software tools be installed on their desktops for their convenience.

The students working in general labs normally don't need and, therefore, are not granted any special software permissions or privileges to complete their assignments (Agarwal, Critcher, Foley, Samati, \& Sigle, 2001; DuBose, 2000; Jones, Tunc \& Cherry, 2000). They log on to desktop computers and operate the programs as ordinary users. For security and license agreement purposes, the lab servers are generally accessible only from within the campus networks. General computing labs is the most common form of computing support among academic institutions.

\section{Configuration 2: Laptop-Ready Classroom}

A laptop-ready classroom can support "hands-on lecture courses" as well as serve as a portable dedicated computing lab (Agarwal et al., 2001; Varvel \& Thurston, 2002). To accommodate this approach, a classroom is furnished with desks equipped with power outlets for laptops. Furthermore, this room is equipped to provide access to secure "wireless LANs" (WLAN). The WLAN security is provided within the confines of IEEE 802.11a, b, g and IEEE 802.1X protocols.

Two separate WLANs may be implemented in this lab. One WLAN can be designed and configured to provide the students with access to the campus computer networks, as well as the Internet. This WLAN will support the students in completing computing assignments and exercises requiring access to campus-wide servers and resources. The second WLAN can be designed and configured as an isolated network that allows access only to designated/local server(s), and, for security reasons, does not provide any connectivity to the campus network or the Internet. This allows students to perform experiments without concerns about violating security and configuration guidelines of the campus network. This WLAN provides computing support for courses such as network administration; system administration and database administration where students need higher network based access privileges.

Two types of laptops may be utilized in this lab: (1) laptops with built-in fixed hard drives and pre-configured operating system and application software, and (2) laptops with removable harddrives. Pre-configured laptops are used in the same capacity as the desktops in the general computing labs, and are loaded with the necessary software to allow access to the servers used for various courses. Students work with these laptops as ordinary users, with no administrator privileges at the operating system level or at the application software level.

The laptops with removable hard-drives, on the other hand, are utilized like the desktops in dedicated computing labs. Students utilizing these laptops are issued blank hard disks at the beginning of the semester and install necessary operating and application software, provided to them, on these disks. Furthermore, students are granted administrative privileges on these laptops and work on projects, exercises and assignments for courses such as System Administration, Network Administration, Network Security, and Database Administration in a "hands-on environment." Incidentally, these students are expected to access and work only within isolated WLAN.

Generally, the laptop computers are loaned to students by the university computing services, and are identical in features and compatible with the hardware/software requirements of the campus networks. Optionally, students may be allowed to use their personal laptop computers in this lab, in which case laptops must satisfy three key criteria. First, the laptop hardware/software must be compatible with the hardware/software requirements of the isolated/campus network hardware/software requirements. Second, the wireless network adapter card address of the laptop computer needs to be registered with the lab administrator to access the secure wireless network. Third, students will need to install the necessary system/application software on their laptop. At the end of the semester, each student's laptop information is cleared from the wireless network 
access database for security reasons. It is noted that the use of student laptops must be allowed only when the networks are considered secure and well-protected.

\section{Configuration 3: Dedicated Computing Lab}

While the students in the general computing category of courses are provided only with ordinary user accounts, the students in the advanced computing courses require privileged access to workstations and servers. Consequently, most of the courses in this category require a dedicated lab (Andleman et al., 2003; Belles \& Miller, 2002; Cherry, Phillabaum, \& Valero, 2000; Dubose, 2000; Wooley, 2003). A dedicated lab can be comprised of an adequate number of networked computers with removable hard drives that are not loaded with any operating system per se. To achieve some additional flexibility, some laptops with removable hard drives may also be included in this lab. For the security of the campus network, this dedicated lab may preferably be kept isolated from the rest of the network. Figure 1 depicts the organization of this lab.

Each row of computers is configured as a separate network and the rows are interconnected to

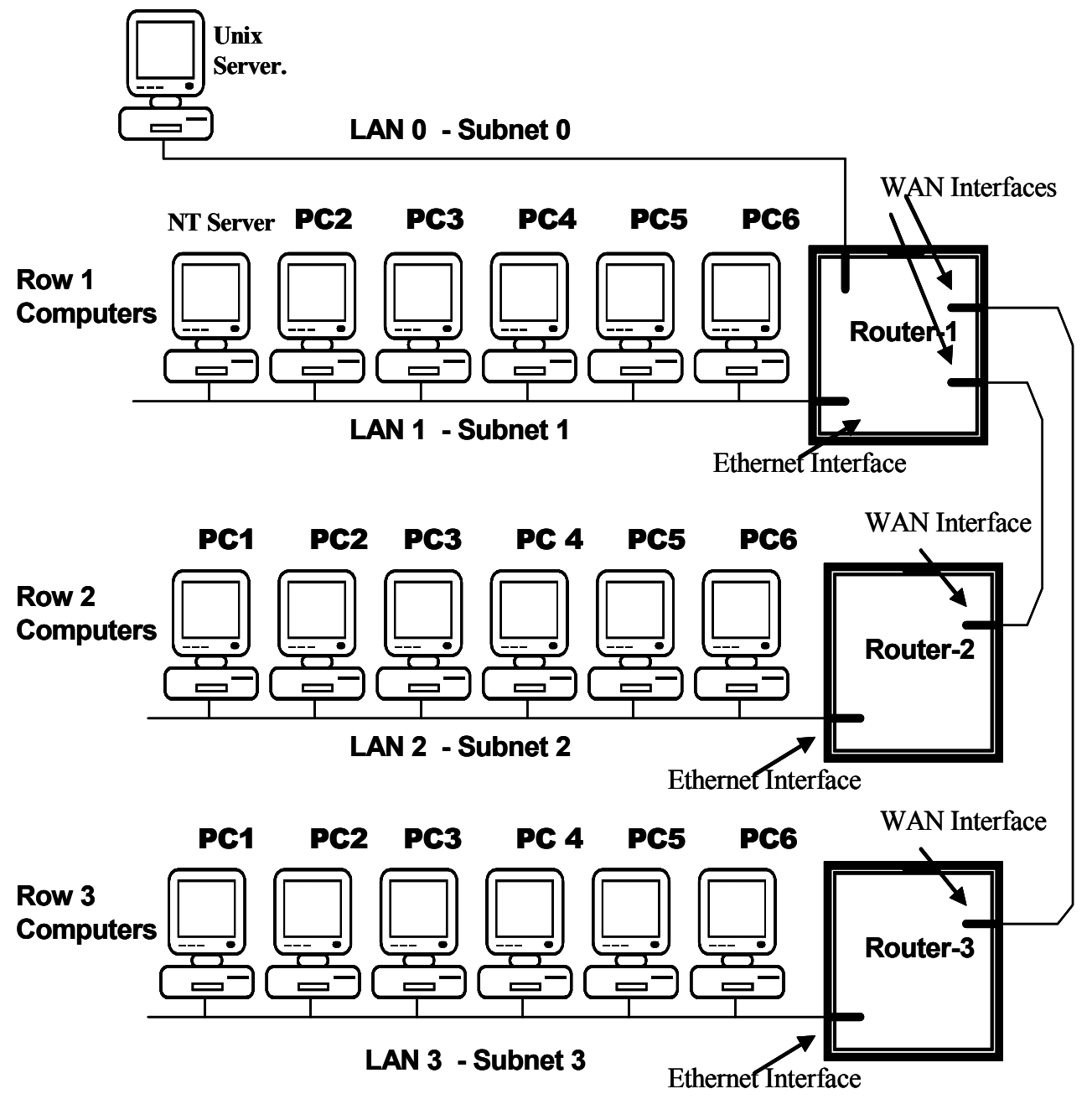

Figure 1: Organization Of The Dedicated Computing Lab 
other rows via routers to create a small Internet within the laboratory. As shown in Figure 1, the end computer in each row is furnished with two network cards for firewall experiments. In a real life scenario, a firewall computer is used to protect a network such as a business LAN from unauthorized access. For this purpose, firewall computers interface with two networks at a time. On one side, they interface with the subnet to be protected via one network card, and, on the other side, they interface with the unprotected network and Internet via another network card. Straddling two networks, firewalls inspect incoming and outgoing traffic for malicious intent and allow or disallow traffic based on the way it is configured.

At the beginning of each semester, students in the courses supported by this lab are loaned re-

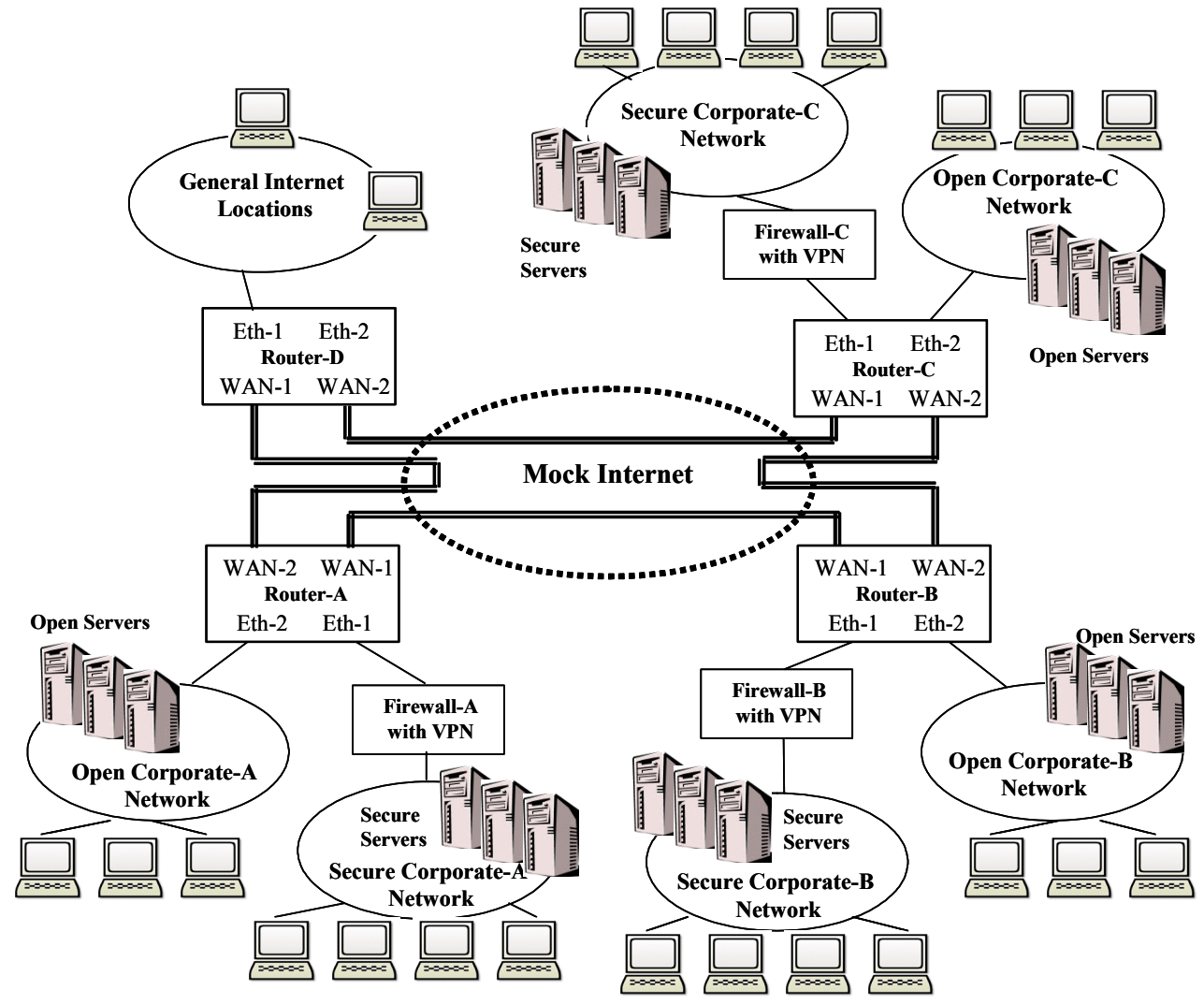

Figure 2: General Configuration Of The Special Projects Lab

movable hard drives with/without an operating system on it. The students are asked to load the hard drives with the necessary operating system and/or application software. Along with the removable hard drives, students are also loaned the CD media for installing the operating system, application programs and the necessary utilities.

Under this lab configuration, students can practice installing and configuring operating systems and application programs without the fear of affecting other users. This allows students to develop skills in System Administration, Database Administration, and Web Server Administration areas. The lab also supports Network Security and related courses by practicing installation of security patches, disabling or reconfiguring services and processes, capturing traffic with protocol analyzer tools, installing firewalls and experimenting with "hacking tools", and so on. 
Computers with removable hard drives offer flexibility and efficiency in supporting multiple courses. However, in order for this to work, any reconfiguration of the lab must be planned with adequate lead time (Belles \& Miller, 2002).

\section{Configuration 4: Special Projects Computing Lab}

The third category of courses is supported by a different lab configuration that may be appropriately labeled "Special Projects Lab." The purpose of this lab is to create a generic IT infrastructure to allow a variety of special projects to be conducted. The IT infrastructure mimics a typical network environment found in an organization. Additionally a mock "Internet" is created using a small WAN (wide area network) to allow experiments in more real life scenarios. The WAN is created with a small number of routers. Each router is furnished with two Ethernet interfaces and two WAN interfaces. Ethernet interfaces are connected to LANs that simulate company LANs. The WAN interfaces are used to interconnect routers to create a simulated WAN. In a real life scenario, WANs are built by leasing digital lines from local or long distance telephone companies. Those lines may sometime span distances in the order of hundreds or thousands of miles. In the Special Projects Lab, in place of leased lines, special router-to-router wiring is used to create the simulated WAN.

Within each LAN, multiple server domains with multiple servers such as file, print, web, database and email servers are created to mimic a typical IT setup found in a business. The domains are designed to support different organizational subunits, such as marketing, sales, and engineering, found in a typical organizational setup. Additionally, to simulate secure and private connectivity found among different organizations or among different geographical locations of an organization, a number of Virtual Private Network (VPN) routers can be setup within this lab. The VPN routers use strong encryption techniques to send and receive data over the Internet to maintain private exchange of business data.

Preferably, this lab should be kept isolated from the general labs. However, some computers outside the lab network may be connected to the campus network and to the Internet. This lab will not only accommodate special projects, it can also be employed to give students hands-on exposure to some sophisticated aspects of the advanced computing courses. Figure 2 illustrates the general configuration of special projects computing lab.

\section{Budgetary Constraints and Solutions}

This section presents various approaches employed by the UHCL MIS department to create dedicated and special projects lab in face of space and budgetary constraints.

Aside from the general computing labs, the laboratories discussed in earlier sections were developed by the MIS department within strict funding limitations. Most of the network hardware used in the dedicated computing lab and special projects lab was acquired in the form of surplus donations from individuals and organizations. Due to lack of skilled personnel, MIS graduate students were recruited to configure and set up the networks in dedicated lab and special projects laboratory. Students were also asked to write configuration documents for those networks for future references. This entire work was conducted as a special project itself with the involvement a number of graduate students. For the special projects lab, students were kept responsible for configuration management and documentation. Documentation was made available to next generation of students. When employing student personnel to develop and maintain computing labs, having these policies and procedure in place is critical to ensure smooth operations of the lab from semester to semester (Dubose, 2000). 
Wherever possible, "waterfall" computers were also utilized to reduce the costs. Waterfall computers are excess computers that are part of periodic replacement of the office and general lab computers at the campus. Waterfall computers were found to be mostly adequate for system administration and networking administration experiments as these involved opening the computers and replacing various components.

The removable hard disks used in laptop lab and in the dedicated computer lab were purchased by the MIS department. However, to reduce acquisition and management costs of hard disks, an institution may opt for requiring students to purchase the hard disks and keep them during their studies.

\section{Conclusion}

Small colleges and universities in US and abroad may need to employ some pragmatic approaches to support their computer science and management information systems programs in face of challenges such as budgetary constraints, lack of physical capacity to house additional computing labs, conflicting computing support needs of different courses, and rapid obsolescence of computing technology. Even large institutions occasionally encounter these challenges in one form or another. This paper presents alternate lab configurations that were designed and implemented in face of these challenges to support computing needs of MIS Department at UHCL. The following list summarizes the lessons learnt at UHCL during this process and can serve as a checklist or reference framework for other institutions facing similar challenges.

- Need for alternative computing lab configurations may arise out of budgetary constraints, lack of physical space to house additional computing labs, conflicting computing needs of different courses, and rapid obsolescence of computing technology.

- To alleviate the problem of the lack of space to house computing labs, a regular classroom can be converted to a laptop-computing lab, allowing the flexibility of using the room as a computing lab as well as a classroom.

- Supporting multiple courses such as Network Administration, System Administration, Database Administration, and Web Administration with a single lab, developed with computers with removable hard drives, provides synergies and efficiencies.

- For courses and projects requiring unique computing support that is normally unavailable in general or dedicated computing labs, a special project lab should be developed. This lab should have generic IT infrastructure that mimics the IT infrastructure in a typical organization and must be able to support diverse and unique computing support requirements.

- For courses that require students to open a computer, replace its components and reconfigure it, surplus computers can be used. It will reduce lab hardware costs. Furthermore, opening a new computer may void its warranty.

- Senior students may be enrolled in a special topics course to help maintain the labs. This will impart valuable experience to these students and at the same time contain personnel costs.

The suggested lab configurations should help small US as well as international institutions that face budgetary and physical space constraints in developing/reconfiguring computing labs to support their computing-related programs. 


\section{References}

Agarwal, K. K., Critcher, A., Foley, D., Samati, R., \& Sigle, J. (2001). Setting up a classroom lab. Journal of Computing in Small Colleges, 16 (3), 281-286.

Andleman, R., Gruver, J., Smith, M., Pirazzi, M., Wilson, L., \& Kimmel, A. (2003). Dynamic labs using a modular configuration. Journal of Computing Sciences in Colleges, 18 (5), 280-281.

Belles, R. \& Miller, J. R. (2002). Multi-purpose specialty labs: Providing specialized computer labs. Journal of Computing Sciences in Colleges, 17 (3), 46-52.

Cherry, D., Phillabaum, P., \& Valero, P. (2000, October). Living on the bleeding edge: Creating and managing highly specialized student labs. SIGUCCS, 40-49.

Dubose, K. (2000, October). Manage all the computer labs on campus? What did I do to deserve this?" SIGUCCS, 74-78.

Jones, C. (2000, October). Opening computing labs, opening minds. SIGUCCS, 130-132.

Jones, C., Tunc, Y., \& Cherry, D. (2000, October). Approaches to computer lab management: lockdown vs. freedom. SIGUCCS, 127-129.

Kumar, A. N. (2003). The effect of closed labs in Computer Science 1: An assessment. Journal of Computing Sciences in Colleges, 18 (5), 40-48.

Lovgren, T. (2000, October). Strategies for implementing unmanned labs. SIGUCCS, 88-92.

Varvel, V. E. Jr., \& Thurston, C., (2002). Perceptions of a wireless network. Journal of Research on Technology in Education, 34 (7), 487-501.

Walter, J. E., (1993, November). Security in unattended computing labs: Safeguarding users as well as machines. SIGUCCS, 267-271.

Wilson, J. H., (2002, November). Recipe to lab management. SIGUCCS, 298-300.

Wooley, B. A., (2003). Utilizing a computing lab to improve retention and recruiting of computer science and computer information science students. Journal of Computing Sciences in Colleges, 18 (3), 228234.

\section{Biographies}

Gokhan Gercek is an Assistant Professor of Management Information Systems at School of

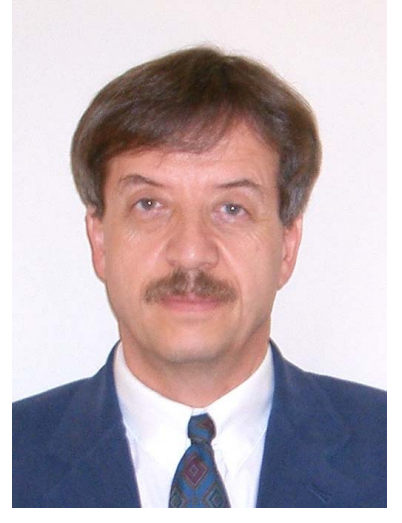
Business, University of Houston-Clear Lake, Houston, Texas, USA. He received his Ph.D. in Electrical and Computer Engineering from Arizona State University in 1986, and joined the Electrical and Computer Engineering Department, Iowa State University, as a tenure-track faculty. In 1989, he joined Lockheed-Martin Corporation as a principal engineer in Houston, Texas, and worked at various NASA, USA, programs and projects through Lockheed-Martin. Furthermore, he also consulted in computer networking and computer security areas. In 2002, he joined University of Houston-Clear Lake. Dr. Gercek has presented several research papers in professional conferences and seminars. His primary research interests include computer network design, network security, and network performance. 
Naveed Saleem is Professor of Management Information Systems at the University of Houston-

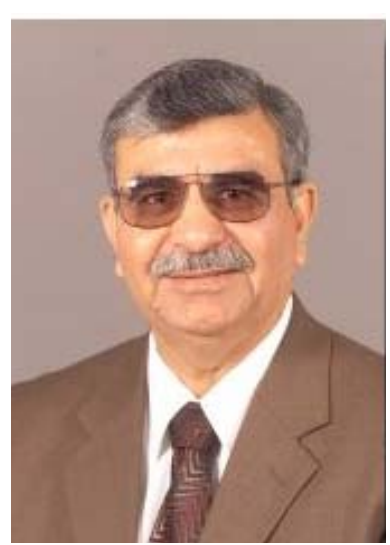
Clear Lake. He earned his Ph.D. in Management Science and Information Systems from the University of Texas at Austin in 1989. His research interests include system development strategies; database development, administration and security; web database applications; data warehousing; data mining; etc. His research papers have been published in Journal of Management Information Systems, Management of End-User Computing, Computer Personnel, Software Development Strategies, EDP Audit and Security, Journal of Nursing Administration, Computers in Nursing, Handbook of IS Management, International Journal of Commerce and Management, and Journal of Business Disciplines. He is also Oracle Certified Professional as Application Developer, Database Administrator, and Database Operator. 